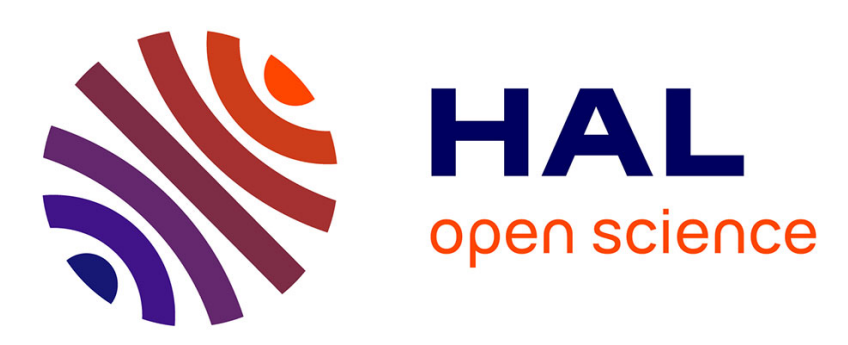

\title{
Socially mediated overlap in vocal interactions between free-ranging black howler monkeys
}

Margarita Briseno-Jaramillo, Mélissa Berthet, Alejandro Estrada, Veronique Biquand, Alban Lemasson

\section{- To cite this version:}

Margarita Briseno-Jaramillo, Mélissa Berthet, Alejandro Estrada, Veronique Biquand, Alban Lemasson. Socially mediated overlap in vocal interactions between free-ranging black howler monkeys. American Journal of Primatology, 2021, 83 (8), pp.e23297. 10.1002/ajp.23297 . hal-03331826

\author{
HAL Id: hal-03331826 \\ https://hal.science/hal-03331826
}

Submitted on 15 Sep 2021

HAL is a multi-disciplinary open access archive for the deposit and dissemination of scientific research documents, whether they are published or not. The documents may come from teaching and research institutions in France or abroad, or from public or private research centers.
L'archive ouverte pluridisciplinaire HAL, est destinée au dépôt et à la diffusion de documents scientifiques de niveau recherche, publiés ou non, émanant des établissements d'enseignement et de recherche français ou étrangers, des laboratoires publics ou privés. 
Socially mediated overlap in vocal interactions between free-ranging black howler monkeys.

3 Briseño-Jaramillo, M. ${ }^{1,2 *}$, Berthet, M. ${ }^{2,3,4}$, Estrada, A. ${ }^{2}$, Biquand V. ${ }^{4}$, Lemasson A. ${ }^{4,5}$

$4 \quad{ }^{1}$ Instituto de Neuroetología, Universidad Veracruzana, Xalapa, Ver., México.

$5 \quad{ }^{2}$ Universidad Nacional Autónoma de México. Instituto de Biología, Coyoacán, 04510. México City. ${ }^{3}$ ENS, Institut Jean Nicod, Département d'études cognitives, ENS, EHESS, CNRS, PSL Research

7 University, 75005 Paris, France.

$8{ }^{4}$ Univ Rennes, Normandie Univ, CNRS, EthoS (Ethologie Animale et Humaine) UMR6552, F9 35000, Rennes, France.

$10 \quad{ }^{5}$ Institut universitaire de France, Paris.

11 * Corresponding author: mar.briseno.jaramillo@gmail.com, tel +525531072054

Abstract: “Conversation rules” such as overlap avoidance and coordinated overlap have been reported in nonhuman animals, and seem to be adaptive responses to the requirements of social life. Some species display both patterns in an apparently flexible way, but the social factors mediating their respective usage remain poorly documented. We investigated potential social factors guiding the usage of these temporal rules during collective howling in six free-ranging groups of black howler monkeys (Alouatta pigra). First, we found that adult males’ vocalizations rarely overlap those of other callers while most adult females' calls overlap other members' calls, especially that of other females. Second, whereas some call types (notably affiliative calls) are typically emitted without overlap, roars (agonistic loud calls) overlap more frequently. Third, coordinated overlap is more frequent during inter-group competition. Our findings support the hypothesis that overlap avoidance and coordinated overlap are two different (here sex-related) vocal alliance social behaviors, at least for some nonhuman primates. More comparative investigations are now needed to explore further their evolutionary trajectories in this lineage. 
Behavioural synchronization among individuals is crucial to group-living species (Engel \&

Lamprecht, 1997), which is well illustrated by vocal interactions. In humans, conversations in both modern and traditional cultures universally respect temporal rules, which facilitate mutual attention, comprehensibility and responsiveness (France et al., 2001; Whittaker \& O’Conaill, 1997). These rules typically involve turn-taking, defined as an alternation of utterances between interlocutors and speech overlap avoidance (Sacks et al., 1978; Stivers et al., 2009). The universality of conversational temporal rules across human languages raised the question of their possible biological function and phylogenetic origin (Pika et al., 2018). In the last decade, several studies have described vocal interactions involving turn-taking rules and call overlap avoidance in a broad range of nonhuman exchanges typically involving two to four individuals vocalizing in alternation (“antiphony” pattern), with an inter-call silence interval of up to five seconds ensuring overlap avoidance (review by Pougnault et al., 2020). These so-called “conversation-like” exchanges are used to strengthen social bonds and maintain socio-spatial cohesion (Chow et al., 2015; Snowdon, 2001; Pika et al., 2018; Pougnault et al., 2020).

However, the conversation-like vocal exchange is just one category of vocal interaction pattern found in the primate genera. Other patterns involve more or less occurrences of overlap between callers (Henry et al., 2015; Pougnault et al., 2020). In duets, for example, two individuals synchronise long series of calls or songs using both coordinated overlaps and overlap avoidances in a species-specific predictive way, mostly for mate attraction and guarding (Geissmann, 2002). Also, choruses are vocal interactions comprising loud call types and involving several individuals who overlap their calls in a less predictable temporal way (Greenfield 2016). Choruses are commonly 
used in reproductive and agonistic contexts, such as territory defence or intergroup space regulation

52 (Chivers, 1969).

It thus remains unclear what selection pressures guided the evolution of call overlap vs overlap-avoidance patterns. According to Yoshida \& Okanoya (2005), the evolutionary pathway suggests that overlap is more ancestral: overlap among several individuals (choruses) may have led to the emergence of overlap between two individuals (duets) and then to antiphony, under the influence of both natural and sexual selection pressures. However, a single species can regularly exhibit different patterns: in some cases, individuals can flexibly switch between different temporal organisations in a context-dependent way (Pougnault et al., 2020), suggesting that temporal patterns are different strategies used to broadcast motivations and regulate social interactions. For example, baboons emit within-group diurnal vocal antiphonies (Rendall et al., 2000) and choruses during group encounters notably at dawn (Kitchen et al., 2003). The sex of callers can also influence the temporal structure of the vocal interactions. In guenons, females call preferentially in antiphony, while males either call alone or chorus with other conspecifics or heterospecific males (Gautier \& Gautier, 1977; Lemasson et al., 2010). This flexibility is also found in other taxa. For example, bottlenose dolphins produce whistles in antiphony to coordinate social activities (Janik, 2000) and in choruses during pre-sleep activities (Kremers et al., 2014), while caciques and nightingales use two song types respectively associated with choruses and antiphonies (Thieltges et al., 2014; Naguib et al., 2002). temporal patterns in a species presenting both overlap and overlap avoidance, like howler monkeys (Baldwin \& Baldwin, 1976; Whitehead 1995). Howler monkeys live in multi-male multi-female groups (Kitchen, 2000), and are famous for their collective loud calls emitted a few times per day by one or several group members (Sekulic, 1982). This howling behaviour has been proposed to fulfil several functions, such as mate defence (da Cunha \& Jalles-Filho, 2007), mate attraction (Bolt, 
2013; Farmer et al., 2011; Whitehead, 1989), resource defence (Bolt et al., 2019, 2020; da Cunha \&

Byrne, 2006; Van Belle et al., 2014a) and regulation of inter-group spacing (da Cunha \& Byrne,

2006; Kitchen et al., 2015) by mutual avoidance or regular advertisement of occupancy (A. pigra,

Kitchen et al., 2015; Van Belle \& Estrada, 2020) or active defence of borders (da Cunha \& JallesFilho, 2007).

Because they are composed of hundreds of calls emitted by several individuals for several minutes in a row (Kitchen, 2004), howling bouts may at first sight appear a chorus with little to no predictable temporal or social coordination. However, a growing body of evidence shows that they participation is optional: the number of males and females joining a howling bout is contextdependent. Overall, females call less than males (da Cunha et al., 2015; Briseño-Jaramillo et al. 2017), but join the chorus when the number of rival males exceeds the number of males in their groups (Kitchen, 2006). Alpha males tend to participate more when vulnerable offspring are present term relationships with the alpha male (Kitchen et al., 2004). Second, howling bouts present a high degree of call overlap but also short silence pauses (da Cunha et al., 2015). Third, the structure of the howling bout can vary i) at the bout level, with the proportion of call types varying with the context of emission and sex of the caller(s) (da Cunha et al., 2015; Kitchen et al., 2015; BriseñoJaramillo et al., 2017) and ii) at the call level, with variations of the acoustic structure of the calls and the duration of vocal responses with the identity of the caller (Briseño-Jaramillo et al., 2015a;

Ceccarelli et al., 2021).

While females sometimes join the howling bouts, most studies have focused on male loud calls. The justification of this bias is twofold. First, males are more involved than females in the defence of their home range and the regulation of inter-group spacing (Sekulic, 1982; Kitchen, 2004). Second, howling bouts are composed of entwined vocal emissions of several individuals, 
which make it hard to unravel each individual's utterance. Since males have a larger hyoid bone and larynx than females, they have louder and deeper voices (Schön, 1971; Dunn et al., 2015), which easily mask female calls (Bergman, 2010; Calegaro-Marques \& Bicca-Marques, 1995; da Cunha et al., 2015; Oliveira, 2002). The lack of studies on female loud calls leads to a knowledge gap of the precise sex-dependent social and temporal organization of the howling bouts.

In this study, we propose to fill this gap by investigating the factors influencing the flexible use of temporally-ruled vocal patterns of howling bouts of black howler monkeys (Alouatta pigra). This species lives in relatively small groups (1-3 adult males and 1-4 adult females, Kitchen 2000) compared to other howler monkey species (Crockett \& Eisenberg, 1987), which allowed us to unravel each individual's participation in a given howling bout. Moreover, the complete vocal repertoire of A. pigra has already been described elsewhere (Briseño-Jaramillo et al., 2017). We conducted our work on six free-ranging groups of A. pigra in the Palenque National Park, Mexico. We focussed on the social function of temporal rules, i.e., overlap avoidance and coordinated overlap. We predicted that the use of specific temporal rules would vary with social factors, notably the callers' characteristics (age and sex of the caller, sex of the caller's partner) and audience context (presence and distance of neighbouring group, if any). Since males produce more conspicuous vocalizations and are more involved in space regulation than females, we expected them to display an antiphony pattern, in order to convey reliable and clear information about the group’s fighting capacity to neighbouring groups and to socially coordinate for a more efficient within-group coalition. Females, on the contrary, emit softer vocalizations, occasionally participate in howling bouts and bond more strongly (Pope, 2000). As such, we expected them to overlap in a coordinated way with other females, in order to increase their chances of being heard and reinforce intra-group cohesion. In line with the hypothesis that coordinated overlap serves a demonstrative function (Pougnault, 2020), we also expected overlap to be associated with more agonistic call types and with high arousal contexts such as inter-group encounters. 
127 Study sites and groups

128 We observed six free-ranging social groups of black howler monkeys (Alouatta pigra). We collected 129 data from mature and immature individuals, i.e., respectively more and less than five years old 130 (Carpenter 1965; Balcells \& Baró 2009; Benitez-Malvido et al., 2016). Infants, still depending on 131 their mothers for locomotion and feeding were not sampled here. Group compositions and sampling 132 efforts are given in Table 1. All individuals were well habituated to human presence and were 133 identified using physical features such as body size, genital pigmentation, permanent scars and botfly 134 marks (Briseño-Jaramillo et al., 2015a; Van Belle et al., 2009, 2014b).

Four groups (BA, MT, PK, MG) lived in the Palenque National Park (PNP, 17²7’51” N, $\left.99^{\circ} 01^{\prime} 30^{\prime \prime} \mathrm{W}\right)$, a Mayan archaeological site. The park is a 1771 ha area including 597 ha of primary tropical rainforest (including 100-200 ha of buried Mayan city ruins), 300 ha of regenerating forest and 874 ha of pasture land (Díaz Gallegos, 1996). The study groups have known adjacent home ranges and are all surrounded by neighbouring groups (Briseño-Jaramillo et al., 2015a; Van Belle et al., 2012; Estrada et al., 2002). The two other groups (CK, QL) lived in fragment forest patches, including agricultural lands, urban areas with dispersed trees and secondary forest areas and located $10.3 \pm 8.4$ km from PNP. The groups living in fragment forest patches were isolated, i.e., they were not surrounded by neighbouring groups.

Our research complied with protocols of the Animal Care Committee of Universidad approved by the Direccion General de Vida Silvestre (SEMARNAT), permit SGPA/DGVS/00692/08. 
Three groups (PK, MT, BA) were followed by MBJ with one or two assistants in Feb. - Jul. 2012, and the three other groups (MG, CK, QL) were followed by MB and one or two assistants in Feb. - May. 2014. For logistic reasons, PK, MT and BA were followed from 06:00 to 18:00 while QL and CK were followed from 05:30 to 9:00 and from 15:30 to 18:00, and MG was followed from 06:00 to 17:00.

All howling bouts emitted by the focal group were recorded. A directional microphone (SONY ECM-672) and a tie microphone (EUROPSONIC ECM 104) connected to a digital audio recorder (MARANTZ PMD661) were used for the recordings (Sample rate $44.1 \mathrm{kHz}$, resolution $16 \mathrm{bit}$, WAV format). The first track was used to record monkeys' calls and the second track was used for comments. All recordings were made at comparable distances (i.e. 20 to 30 meters). We considered a bout as a period of synchronized loud roaring separated by more than one minute of silence from any other loud roaring bout (Briseño-Jaramillo et al. 2017). During the howling bout, the two or three observers spread around the group to reliably identify the identity of the provider for each call. This was made possible because of the relatively limited group size, high spatial cohesion and low vegetation density. The observers thus identified in the field each caller and commented on its identity, simultaneously to each call emission.

The context of emission of the howling bout was also commented at the beginning of the howling event: this comprised whether a neighbouring group was present, and if so, whether this neighbouring group was close (directly visible by the observer, typically within $30 \mathrm{~m}$ ) or far (not visible but auditorily spotted via branch cracking and/or vocalisations, typically between 30 and $100 \mathrm{~m})$. The times when each bout started and ended were also collected.

\section{Data processing}

Howling sequences involving a single caller were discarded as we focussed on social coordination. Also, only howling bouts from focal group were considered in this study. Howling bouts are 
173 composed of series of calls from different call categories. The vocal repertoire of howling bouts of

174 black howler monkeys A. pigra have been previously defined (Briseño-Jaramillo et al., 2017). It

175 comprises six acoustically and functionally call categories (Briseño-Jaramillo et al., 2017): "barks”

176 (typical bark and soft bark), "roars”, "roar variants” (frequency modulated roar and soft roar),

177 “agonistic calls” (metallic cackling notes and coo), “affiliative calls” (barked grunt, soft scream and 178 moo) and "grunts", easily discriminable by stereotypic acoustic patterns. Using Avisoft-SASLab Pro 179 (Berlin, Germany) software, we built spectrograms with Fast Fourier transformation (FFT) and a 180 time window of 256 points. These spectrograms were used to score, for each call recorded: 1) the 181 call type name and 2) the presence / absence of overlap (i.e., whether the call started before the end 182 of a call from another group member) (see Fig. 1). We also reported from the comment track, for 183 each call: 3) the identity of the caller and 4) the context of emission. We coded a total of 112 184 howling bouts (see Table 1), comprising a total of 76,726 calls. Howling bouts lasted on average $18511 \mathrm{~min} 48 \mathrm{~s} \pm 05 \mathrm{~min} 49 \mathrm{~s}$ and were composed of a mean of $541.9 \pm 521.7$ SD calls per bout. recorded a howling bout (group QL, 5 min/calls) and separately coded callers’ identities and call types. Although the precise threshold for a "substantial” inter-rater agreement is still debated (Haligren, 2012), we found here a relatively strong agreement between our two observers given the complexity of our data set (Cohen’s kappa test: k=0.73, Landis \& Koch, 1977).

Statistical analysis

To address all our research questions and due to non-normal distribution of our data, we built generalized linear mixed models (GLMMs). Since our dependent variable was the presence or absence of overlap for each call occurrence, we fitted our mixed models with a Binomial error structure (Zuur et al., 2009). We built a null model, which only included the random factors as intercepts (i.e., group identity, caller identity and howling bout) and several full models, which 
additionally included the fixed effects. We compared the null to each full model using a likelihood ratio test (LRT) using an ANOVA (Zuur et al., 2009). If the LRT was significant $(\mathrm{P}<0.05)$, we performed Tukey post hoc comparisons with the multcomp package on the full model (function glht in R, Hothorn et al., 2008).

- The first full model (GLMM1) assessed the influences on vocal overlap of callers’ characteristics and call type. Fixed factors for this GLMM were thus the age (mature and immature, see Table 1), the sex (male or female) and the call type (i.e., six abovementioned call types). This analysis was done with all studied groups (monkey groups $\mathrm{N}=6$; howling bouts $\mathrm{N}=112$; calls $\mathrm{N}=76,726)$.

- The second full model (GLMM2) assessed the influence of contextual variations. We thus included fixed factors: neighbouring groups absent, close or distant. Only four groups (PNP only) could be included in this analysis as the two others had no neighbours (monkey groups $\mathrm{N}=4$; howling bouts $\mathrm{N}=93$; calls $\mathrm{N}=67,736$ ).

- The third full model (GLMM3) assessed whether the sex of the caller’s partner influenced the overlap behaviour of the caller, i.e., whether male and female preferred to overlap calls from other males or females. To this end, we included sex of the partner as fixed factor. In this model, we could only include two monkey groups (PN, BA), i.e., those where callers had the possibility to overlap the same probability of females and males (PN: 3 mature females and 3 mature males / BA: 2 mature females and 2 mature males) (monkey groups $\mathrm{N}=2$; howling bouts $\mathrm{N}=64$; calls $\mathrm{N}=43,546$ ).

Additionally, we tested for overdispersion (i.e., if the variance was larger than the mean in our dependent variable) and result indicated no overdispersion for each of our models (values should ideally be lower than 1.4): 0.58 (GLMM1), 0.74 (GLMM2) and 0.66 (GLMM3). We also tested the stability of each model (for assessing overall influence over the model fit) by comparing the estimates derived from a model based on all data with those obtained from models without identified 
221 influential individuals (Nieuwenhuis et al., 2012). All the models remained significant after this

222 procedure. The fit of the models was evaluated as the proportion of variance explained by the

223 marginal coefficient of determination $\mathrm{R}^{2}$, (i.e., the variance accounted for by fixed factors), and the

224 conditional coefficient of determination $\mathrm{R}^{2}$ (i.e., the variance accounted for by both fixed and

225 random factors) according to the method described in Nakagawa \& Schielzeth (2013). All model

226 outputs are resumed in the Appendix 1, 2 and 3.

Statistical analyses were conducted using R version 3.5.2 (R Core Team 2016). GLMMs were

designed using the lme4 package (Bates et al., 2014), LRT tests were conducted with the ANOVA

229 function (Zuur et al., 2009), overdispersion was calculated using the blmeco package (function

230 dispersion.glmer in R, Korner-Nievergelt et al., 2015), stability of models was assessed using the

231 Cook’s distance in the influence.ME package (Nieuwenhuis et al., 2012), fits of the models were

232 calculated with the "performance” package and we used the ggeffects package in R (Lüdecke et al., $2332020)$ to draw graphics.

\section{RESULTS}

1) Influence of callers' identity and call type - bias on rates of vocal overlap

The full model $\left(\mathrm{R}_{\mathrm{m}}^{2}=0.891, \mathrm{R}_{\mathrm{c}}{ }_{\mathrm{c}}=0.429\right)$ was significantly different from the null model 
245 identity (sexes: $\chi^{2}=119.064, \mathrm{P}<0.0001$; age: $\left.\chi 2=17.984, \mathrm{P}<0.0001\right)$ and call type $(\chi 2=6837.1$,

$\mathrm{P}<0.0001$ ) significantly influenced vocal overlap.

247 Post hoc Tukey comparisons showed first that immature overlapped more than adult monkeys ( $($ = 248 1.15, $\mathrm{SE}=0.27, \mathrm{Z}=4.24, \mathrm{P}<0.0001)$ (Fig. 2) and females overlapped more often than males $(ß=-$ 3.09, $\mathrm{SE}=0.28, \mathrm{Z}=-10.91, \mathrm{P}<0.0001)$ (Fig. 2).

Second, roars overlapped more often than did affiliative calls $(ß=6.69, \mathrm{SE}=0.26, \mathrm{Z}=25.6, \mathrm{P}<$

0.0001), barks ( $(=5.96, \mathrm{SE}=0.08, \mathrm{Z}=78.09, \mathrm{P}<0.0001)$, grunts $(ß=1.4, \mathrm{SE}=0.08, \mathrm{Z}=18.44, \mathrm{P}<$

0.0001 ) and roar variant calls $(ß=-1.66, \mathrm{SE}=0.04, \mathrm{Z}=-38.92, \mathrm{P}<0.0001)$, but did not differ from

agonistic calls $(ß=0.34, \mathrm{SE}=0.27, \mathrm{Z}=1.25, \mathrm{P}=0.77)$. Agonistic calls overlapped more often than

affiliative calls ( $(=6.34, \mathrm{SE}=0.36, \mathrm{Z}=17.6, \mathrm{P}<0.0001)$, barks $(ß=-5.62, \mathrm{SE}=0.27, \mathrm{Z}=-20.38$,

$\mathrm{P}<0.0001$ ), grunts $(ß=-1.10, \mathrm{SE}=0.27, \mathrm{Z}=-3.98, \mathrm{P}<0.0001)$ and roar variants $(ß=-1.32, \mathrm{SE}=$

0.27, $\mathrm{Z}=-4.88, \mathrm{P}<0.0001)$. Roar variants overlapped more often than affiliative calls ( $ß=5.02$, $\mathrm{SE}$

$=0.26, \mathrm{Z}=19.49, \mathrm{P}<0.0001)$ and barks $(ß=4.30, \mathrm{SE}=0.08, \mathrm{Z}=55.06, \mathrm{P}<0.0001)$ but not than

grunts ( $ß=-0.22, \mathrm{SE}=0.08, \mathrm{Z}=2.72, \mathrm{P}=0.05)$. Grunts overlapped more often than barks $(ß=4.53$,

$\mathrm{SE}=0.10, \mathrm{Z}=44.12, \mathrm{P}<0.001)$ and affiliative calls $(ß=5.25, \mathrm{SE}=0.26, \mathrm{Z}=19.79, \mathrm{P}<0.001)$.

Affiliative calls overlapped more often than barks ( $(=0.72, \mathrm{SE}=0.26, \mathrm{Z}=2.78, \mathrm{P}=0.04$ ) (Fig. 3).

2) Influence of contextual variations of vocal overlap

The full model $\left(\mathrm{R}_{\mathrm{m}}^{2}=0.889, \mathrm{R}_{\mathrm{c}}{ }_{\mathrm{c}}=0.053\right)$ was also significantly different from the null

model $\left(\mathrm{R}_{\mathrm{m}}^{2}=0.892, \mathrm{R}_{\mathrm{c}}{ }_{\mathrm{c}}=0.000\right),\left(\mathrm{LRT}: \chi^{2}=1518, \mathrm{P}<0.0001\right)$. The model showed that neighbour context influenced the variations of vocal overlap $(\chi 2=1423.06, \mathrm{P}<0.0001)$. Post hoc Tukey comparisons showed that overlap increased when a neighbouring group was present and close comparing to situations where neighbours were absent ( $ß=2.66, \mathrm{SE}=0.09, \mathrm{Z}=30.21, \mathrm{P}<0.0001$ ) or distant $(ß=-2.42, \mathrm{SE}=0.06, \mathrm{Z}=-3751, \mathrm{P}<0.0001)$. Moreover, overlap increased when a 
neighbouring group was distant compared to when no neighbour was around $(\Omega=0.23, \mathrm{SE}=0.06, \mathrm{Z}$

\section{3) Influence of partners’ sex on preferred targets of overlap:}

The full model $\left(\mathrm{R}_{\mathrm{m}}^{2}=0.894, \mathrm{R}_{\mathrm{c}}{ }_{\mathrm{c}}=0.169\right)$ was significantly different from the null model $273\left(\mathrm{R}_{\mathrm{m}}^{2}=0.889, \mathrm{R}_{\mathrm{c}}^{2}=0.053\right),\left(\mathrm{LRT}: \chi^{2}=915.55, \mathrm{P}<0.000\right)$ and showed sex-differences in the overlap behaviours $(\chi 2=595.11, \mathrm{P}<0.0001)$. Post hoc Tukey comparisons showed that female - female (i.e.,

a female overlaps the previous call of another female) were more frequent than female - male (i.e., a female overlaps the previous call of another male) $(ß=-4.07, \mathrm{SE}=0.21, \mathrm{Z}=-19.0, \mathrm{P}<0.0001)$, male - female $(ß=-5.17, \mathrm{SE}=0.35, \mathrm{Z}=$-15.0, $\mathrm{P}<0.0001)$ and male - male $(ß=-.5 .9, \mathrm{SE}=0.35, \mathrm{Z}=$ 17.31, $\mathrm{P}<0.0001$ ) overlaps (Fig. 5). Also, female - male overlaps were more frequent than male female $(ß=-1.06, \mathrm{SE}=0.32, \mathrm{Z}=-3.41, \mathrm{P}=0.003)$ and male - male $(ß=-1.9$, $\mathrm{SE}=0.32, \mathrm{Z}=-5.79$, $\mathrm{P}<0.0001$ ) overlaps. Finally, male - female overlaps were more frequent than male - male overlaps $(ß=-0.75, \mathrm{SE}=0.06, \mathrm{Z}=-12.27, \mathrm{P}<0.0001)$ (Fig. 5).

\section{DISCUSSION}

Our study confirms that, far from being choruses with non-obvious temporal organizations, black howler monkeys’ howling bouts are non-random coordinated vocal interactions. Both overlap avoidance and coordinated overlap are frequent but sex-dependent, suggesting, as predicted, a coexistence of two different strategies of vocal interaction and social synchronization: adult males avoid call overlap, while females and immature subjects typically overlap their calls (i.e., two or more individuals emit calls simultaneously). The sex of the overlapped partner also matters: females principally overlap other females’ calls. Finally, overlap preferentially involves call types (such as roars and so-called agonistic calls) known to have an agonistic function (Baldwin \& Baldwin, 1976; during agonistic group encounters with close neighbour groups (Briseño-Jaramillo et al., 2017). 
293 Overall, our findings suggest that temporal rules of howling bouts have social functions as discussed 294 below.

Overlap avoidance appears to be a "between-males" temporal rule, which could be used for territory defence, inter-group spacing, as well as for intra-group socio-spatial coordination. Males call more often and their call rates are higher than those of females and form the core of a howling bout (Briseño-Jaramillo et al., 2017). Typically, the alpha male calls more frequently and sometimes alone, but when the situation becomes particularly tense (e.g., when a neighbouring group is present), other male group members join the howling bout (Kitchen, 2006) and form coalitions or "vocal alliances.” Calling together could reinforce the coalition between resident males by motivating one another and announce occupancy to the neighbours (Kitchen, 2000), which aims to regulate inter-group spacing and to protect home range borders (Sekulic, 1982; Kitchen, 2000;

Garber \& Kowalewski, 2011; Van Belle et al., 2014a). Male territorial neighbours can be individually recognized by their voices, and neighbouring males who are not at their usual place are particularly counterattacked (Briseño-Jaramillo et al. 2015a). Also, howler monkeys can discriminate the number of opponent males based on neighbours' howling bouts and adjust their behaviour according to the risk (Kitchen, 2000). If male calls overlapped, it could be difficult for neighbouring males willing to defend the territory. Also, males from a given group can defend different parts of the territory border (Stanford, 1998) but can lose sight of each other among the dense vegetation. Overlap avoidance can thus help coordinate intra-group collective movements. This is in line with the suggestion that males call in antiphony (Briseño-Jaramillo et al., 2015b), but turn-taking per se 315 (e.g., the number of successive turns) was not investigated in the present study and remains to be more deeply studied. 
Conversely, coordinated overlap appeared to be a "between-females" temporal rule. For

decades, the vocal role played by adult howler monkey females has attracted little to no attention.

We now know that females sometimes join howling bouts (Kitchen, 2006), and are able to produce most of the supposedly male call types (Briseño-Jaramillo et al., 2017). However, females are more discreet than males. They call less frequently than males, do not always join in males' howling displays (Kitchen, 2006) and never howl without male accompaniment (Kitchen, 2000). Moreover, they call more during howling bouts in intergroup encounters compared to spontaneous howling (Van Belle, 2015). Playback studies revealed that they are able to assess their group’s relative fighting ability and reserve their participation for contests with less predictable outcomes (Kitchen, 2006). Moreover, female calls are much softer (Whitehead, 1987). The fact that females overlap their calls almost exclusively with those of other females could be a way to produce louder sounds in "unison.” The fact that immature individuals also do so is in line with the idea that this vocal strategy is used to compensate for relatively non-loud voices. This vocal strategy could also function to strengthen or to advertise female cohesion: indeed, females from the same group form strong bonds (e.g., greater spatial proximities and less agonism among females than among males, Van Belle et al., 2011) and are intolerant towards unfamiliar females (Pope, 2000). In conclusion, call overlap in females may have extra-group and intra-group functions, such as reinforcement of intra-sex cohesion and territory defence. Whether females joining the howling bouts has an influence on the outcome of the communicative event remains, however, to be experimentally investigated.

Even if females overlap more often than males, males also do so on some occasions. Overall, overlap was associated with more agonistic calls and more agonistic communicative contexts, which is in line with our hypothesis that this power-demonstrating strategy plays a possible deterrent role. Encounters with neighbours, particularly when the situation becomes critical, are associated with very high arousal where males and females join forces (Neville et al., 1988), and individuals display all sorts of arousal-related behaviours such as piloerection, breaking branches, and embracing 
342 (Kitchen 2000). The fact that overlap is associated with strong agonism confirms that this temporal 343 rule fulfils a social function. More studies, notably playback experiments, are now needed to 344 evaluate whether temporal rules (coordinated overlap and overlap avoidance) affect the information 345 transfer among groups and impact the behavioural response of receivers.

Some authors previously classified howler monkeys’ howling bouts as rather disorganized choruses primarily functioning in inter-group communication (Chivers 1969; Baldwin \& Baldwin 1976; Sekulic 1982). Here, we firstly show that howling bouts are non-randomly organised, which fulfils both inter-group and intra-group functions. Indeed, call overlap and overlap avoidance seems to play a role in competition regulation and group cohesion. Both coordinated overlap and overlap avoidance could be found here serving sex-specific and context-dependent functions. Our results thus confirm that $A$. pigra is an interesting species to investigate the evolution of temporal rules in vocal communication. Investigating the organization of communication in species that use more than one temporal rule is particularly interesting to highlight and understand the evolutionary pressures acting on this trait and to which extent these rules are socially flexible (Yoshida \& Okanoya, 2005). Running more comparative studies can help to better picture how call use flexibility, vocal interaction patterns and social needs co-evolved in primates, but also at a larger phylogenetic scale. Our study confirms that overlap and overlap avoidance are two vocal strategies that could have evolved in parallel to serve different social functions.

Conflict of interest statement: The authors declare that they have no conflict of interest.

Acknowledgments: We thank the Comisión Nacional de Áreas Naturales Protegidas of Mexico (CONAP) for the permission to work at Palenque National Park and the division of wildlife of the environmental agency of Mexico (Dirección General de Vida Silvestre (SEMARNAT-Mexico); 
permit code SGPA/DGVS/02684/10). Our research was supported by grants from CONACYT (220762), the Graduate Program in Biological Sciences (UNAM), CNRS (PICS program), ANR, IUF, IDEA WILD, the European Research Council (ERC) under the European Union’s Horizon 2020 research and innovation programme (grant agreement No 788077, Orisem, PI: Schlenker) and by grants ANR-10-IDEX-0001-02 and FrontCog ANR-17-EURE-0017. We thank the Institute of Biology (UNAM) and Animal and Human Ethology Laboratory (University of Rennes 1) staff members for administrative and logistical support. We thank assistants (Rogier Hitzen, Maggie May, Elizabeth Unger, Cindy Maslarova, Oskar Persson, Emily Wilson and Gala Enidh Castro Mejias) for support in the field. We are especially grateful to Dr. Sarie Van Belle of the Institute of Biology of UNAM and the University of Texas-Austin for providing general contextual information on the black howler groups studied in Palenque National Park. Thank you to Nora Lewin for the English corrections.

\section{Ethical standards}

Experiments comply with the current laws of Mexico.

\section{Conflict of interest}

The authors declare that they have no conflict of interest.

\section{REFERENCES}

Balcells, C. D., \& Baró, J. J. V. (2009). Developmental stages in the howler monkey, subspecies Alouatta palliata mexicana: a new classification using age-sex categories. Neotropical Primates, 16(1), 1-8. https://doi.org/10.1896/044.016.0101

Baldwin, J. D., \& Baldwin, J. I. (1976). Vocalizations of Howler Monkeys (Alouatta palliata) in Southwestern Panama. Folia Primatologica, 26(2), 81-108. https://doi.org/10.1159/000155733

Bates, D., Maechler, M., Bolker, B., \& Walker, S. (2014). lme4: Linear mixed-effects models using Eigen and S4. R Package Version, 1(7), 1-23. http://dx.doi.org/10.1111/j.1600-0706.2009.17726.x. 
391 Benitez-Malvido, J., Martínez-Falcón, A. P., Dattilo, W., González-DiPierro, A. M., Estrada, R. L., 392 \& Traveset, A. (2016). The role of sex and age in the architecture of intrapopulation howler monkey393 plant networks in continuous and fragmented rain forests. PeerJ, 4, e1809.

394 https://doi.org/10.7717/peerj.1809.

Bergman, T. J. (2010). Experimental evidence for limited vocal recognition in a wild primate: Implications for the social complexity hypothesis. Proceedings of the Royal Society B: Biological Sciences, 277(1696), 3045-3053. https://doi.org/10.1098/rspb.2010.0580

Bolt, L. M. (2013). The function of howling in the ring-tailed lemur (Lemur catta). International Journal of Primatology, 34(1), 157-169. https://doi.org/10.1007/s10764-012-9654-8

Bolt, L. M., Schreier, A. L., Russell, D. G., Jacobson, Z. S., Merrigan-Johnson, C., Barton, M. C., \& Coggeshall, E. M. (2019). Howling on the edge: Mantled howler monkey (Alouatta palliata) howling behaviour and anthropogenic edge effects in a fragmented tropical rainforest in Costa Rica. Ethology, 125(9), 593-602. https://doi.org/10.1111/eth.12886

Briseño-Jaramillo, M., Estrada, A., \& Lemasson, A. (2015a). Individual voice recognition and an auditory map of neighbours in free-ranging black howler monkeys (Alouatta pigra). Behavioral Ecology and Sociobiology, 69(1), 13-25. https://doi.org/10.1007/s00265-014-1813-9

Briseño-Jaramillo, M., Estrada, A., \& Lemasson, A. (2015b)b. Behavioural innovation and cultural transmission of communication signal in black howler monkeys. Scientific Reports, 5(1), 1-10. https://doi.org/10.1038/srep13400

Briseño-Jaramillo, Margarita, Biquand, V., Estrada, A., \& Lemasson, A. (2017). Vocal repertoire of free-ranging black howler monkeys'(Alouatta pigra): Call types, contexts, and sex-related contributions. American Journal of Primatology, 79(5), e22630. https://doi.org/10.1002/ajp.22630

Calegaro-Marques, C., \& Bicca-Marques, J. C. (1995). Vocalizações de Alouatta caraya (Primates, Cebidae). In Ferrari, S.F., Schneider, H. (Eds.), A Primatologica No Brazil (pp. 129-140). A Primatologia no. 5. Brasil: Belém.

Carpenter, C. R. (1934). A field study of the behavior and social relations of howling monkeys. Comparative Psychology Monographs. 10(2), 168.

Ceccarelli, E., Rangel-Negrín, A., Coyohua-Fuentes, A., Canales-Espinosa, D., \& Dias, P. A. D. (2021). Vocal and movement responses of mantled howler monkeys (Alouatta palliata) to natural loud calls from neighbors. American Journal of Primatology, e23252.

https://doi.org/10.1002/ajp.23252

Chivers, D. J. (1969). On the daily behaviour and spacing of howling monkey groups. Folia Primatologica, 10(1-2), 48-102. https://doi.org/10.1159/000155188

Chow, C. P., Mitchell, J. F., \& Miller, C. T. (2015). Vocal turn-taking in a non-human primate is learned during ontogeny. Proceedings of the Royal Society B: Biological Sciences, 282(1807), 20150069. https://doi.org/10.1098/rspb.2015.0069 
Crockett, C. M., \& Eisenberg, J. F. (1987). Howlers: Variations in group size and demography. In B. B. Smuts, D. L. Cheney, R. M. Seyfarth, R. W. Wrangham, and T. T. Struhsaker,, Primate Societies (pp. 54-68). University of Chicago Press, Illinois, USA: Chicago.

https://doi.org/10.7208/9780226220468-008

da Cunha, R. G. T., \& Byrne, R. W. (2006). Roars of black howler monkeys (Alouatta caraya):

Evidence for a function in inter-group spacing. Behaviour, 143(10), 1169-1200.

https://doi.org/10.1163/156853906778691568

da Cunha, R. G. T., \& Jalles-Filho, E. (2007). The roaring of southern brown howler monkeys (Alouatta guariba clamitans) as a mechanism of active defence of borders. Folia Primatologica, 78(4), 259-271. https://doi.org/10.1159/000105545

da Cunha, R. G. T., de Oliveira, D. A. G., Holzmann, I., \& Kitchen, D. M. (2015). Production of loud and quiet calls in howler monkeys. In M. M., Kowalewski, P. A., Garber, L., Cortés-Ortiz, L., B.,Urbani, \& D. Youlatos, Howler Monkeys. Adaptive Radiation, Systematics, and Morphology (pp. 337-368). Springer, USA: New York. https://doi.org/10.1007/978-1-4939-1957-4_13

Díaz Gallegos, J. R. (1996). Estructura y composición florística de la vegetación del parque nacional zona arqueológica de Palenque, Chiapas, México, Universidad Juárez Autónoma de Tabasco, Villahermosa (unpublished doctoral dissertation).

Dunn, J. C., Halenar, L. B., Davies, T. G., Cristobal-Azkarate, J., Reby, D., Sykes, ... Knapp, L. A. (2015). Evolutionary trade-off between vocal tract and testes dimensions in howler monkeys. Current Biology, 25(21), 2839-2844. https://doi.org/10.1016/j.cub.2015.09.029

Engel, J., \& Lamprecht, J. (1997). Doing what everybody does? A procedure for investigating behavioural synchronization. Journal of Theoretical Biology, 185(2), 255-262. https://doi.org/10.1006/jtbi.1996.0359

Estrada, A., Castellanos, L., Garcia, Y., Franco, B., Muñoz, D., Ibarra, A., Rivera, ... Jimenez, C. (2002). Survey of the black howler monkey, Alouatta pigra, population at the Mayan site of Palenque, Chiapas, Mexico. Primates, 43(1), 51-58. https://doi.org/10.1007/BF02629576

Farmer, H. L., Plowman, A. B., \& Leaver, L. A. (2011). Role of vocalisations and social housing in breeding in captive howler monkeys (Alouatta caraya). Applied Animal Behaviour Science, 134(34), 177-183. https://doi.org/10.1016/j.applanim.2011.07.005

France, E. F., Anderson, A. H., \& Gardner, M. (2001). The impact of status and audio conferencing technology on business meetings. International Journal of Human-Computer Studies, 54(6), 857876. https://doi.org/10.1006/ijhc.2001.0464

Garber, P. A., \& Kowalewski, M. K. (2011). Collective action and male affiliation in howler monkeys (Alouatta caraya). In Origins of altruism and cooperation (pp. 145-165). Springer. https://doi.org/10.1007/978-1-4419-9520-9_8 
Gautier, J. P., \& Gautier, A. (1977). Communication in Old World monkeys. In T. A. Sebeok Indiana U. P. How Animals Communicate, (890-964 pp.) Indiana University Press. USA: Bloomington. https://doi.org/10.1002/ajpa.1330500114

Geissmann, T. (2002). Taxonomy and evolution of gibbons. Evolutionary Anthropology: Issues, News, and Reviews, 11(S1), 28-31. https://doi.org/10.1002/evan.10047

Greenfield, M. (2016). Synchronous and alternating choruses in insects and anurans: common mechanisms and diverse. Am. Zool. 34: 605-615. https://doi.org/10.1093/icb/34.6.605

Hallgren, K. A. (2012). Computing inter-rater reliability for observational data: an overview and tutorial. Tutorials in quantitative methods for psychology, 8(1), 23.

https://doi.org/10.20982/tqmp.08.1.p023

Henry, L., Craig, A. J., Lemasson, A., \& Hausberger, M. (2015). Social coordination in animal vocal interactions. Is there any evidence of turn-taking? The starling as an animal model. Frontiers in Psychology, 6, 1416. https://doi.org/10.3389/fpsyg.2015.01416

Hothorn, T., Bretz, F., \& Westfall, P. (2008). Simultaneous inference in general parametric models. Biometrical Journal, 50(3), 346-363. https://doi.org/10.1002/bimj.200810425

Janik, V. M. (2000). Whistle Matching in Wild Bottlenose Dolphins. Science, 289(5483), 1355-1357. https://doi.org/10.1126/science.289.5483.1355

Kitchen, D. M. (2000). Agression and assessment among social groups of belizean black howler monkeys. University of Minnesota, Minneapolis (unpublished doctoral dissertation).

Kitchen, D. M. (2004). Alpha male black howler monkey responses to loud calls: Effect of numeric odds, male companion behaviour and reproductive investment. Animal Behaviour, 67(1), 125-139. https://doi.org/10.1016/j.anbehav.2003.03.007

Kitchen, D. M. (2006). Experimental test of female black howler monkey (Alouatta Pigra) responses to loud calls from potentially infanticidal males: Effects of numeric odds, vulnerable offspring, and companion behavior. American Journal of Physical Anthropology, 131(1), 73-83. https://doi.org/10.1002/ajpa.20392

Kitchen, D. M., da Cunha, R. G. T., Holzmann, I., \& de Oliveira, D. A. G. (2015). Function of loud calls in howler monkeys. Springer. In: M. M., Kowalewski, P. A., Garber, L., Cortés-Ortiz, L., B.,Urbani, \& D. Youlatos, Howler Monkeys. Adaptive Radiation, Systematics, and Morphology (pp. 369-399). Springer, USA: New York. https://doi.org/10.1007/978-1-4939-1957-4_14

Kitchen, D. M., Horwich, R. H., \& James, R. A. (2004). Subordinate male black howler monkey (Alouatta pigra) responses to loud calls: Experimental evidence for the effects of intra-group male relationships and age. Behaviour, 141(6), 703-724. https://doi.org/10.1163/1568539042245196

Kitchen, D. M., Seyfarth, R. M., Fischer, J., \& Cheney, D. L. (2003). Loud calls as indicators of dominance in male baboons (Papio cynocephalus ursinus). Behavioral Ecology and Sociobiology, 53(6), 374-384. https://doi.org/10.1007/s00265-003-0588-1 
498 Korner-Nievergelt, F., Roth, T., Von Felten, S., Guélat, J., Almasi, B., \& Korner-Nievergelt, P. 499 (2015). Bayesian data analysis in ecology using linear models with R, BUGS, and Stan. Academic 500 Press. Elsevier, Amsterdam.

501 Kremers, D., Jaramillo, M. B., Böye, M., Lemasson, A., \& Hausberger, M. (2014). Nocturnal Vocal 502 Activity in Captive Bottlenose Dolphins (Tursiops truncatus): Could Dolphins have Presleep 503 Choruses?. Animal Behaviour Cognition,1(4), 464-469. https://doi.org/10.12966/abc.11.04.2014

Landis, J. R., \& Koch, G. G. (1977). The measurement of observer agreement for categorical data. Biometrics, 33(1),159-174. https://doi.org/10.2307/2529310

Lemasson, A., Gandon, E., \& Hausberger, M. (2010). Attention to elders' voice in non-human primates. Biology Letters, 6(3), 325-328. https://doi.org/10.1098/rsbl.2009.0875

Lemasson, A., Glas, L., Barbu, S., Lacroix, A., Guilloux, M., Remeuf, K., \& Koda, H. (2011). Youngsters do not pay attention to conversational rules: is this so for nonhuman primates?. Scientific reports, 1(1), 1-4. https://doi.org/10.1038/srep00022

Levréro, F., Touitou, S., Fredet, J., Nairaud, B., Guéry, J.-P., \& Lemasson, A. (2019). Social bonding drives vocal exchanges in Bonobos. Scientific Reports, 9(1), 1-11. https://doi.org/10.1038/s41598018-36024-9

Lüdecke, D., Ben-Shachar, M. S., Patil, I., \& Makowski, D. (2020). Extracting, computing and exploring the parameters of statistical models using R. Journal of Open Source Software, 5(53), 2445. https://doi.org/10.21105/joss.02445

Naguib, M., Mundry, R., Hultsch, H., \& Todt, D. (2002). Responses to playback of whistle songs and normal songs in male nightingales: Effects of song category, whistle pitch, and distance. Behavioral Ecology and Sociobiology, 52(3), 216-223. http://dx.doi.org/10.1007/s00265-002-05111.

Nakagawa, S., \& Schielzeth, H. (2013). A general and simple method for obtaining R2 from generalized linear mixed-effects models. Methods in Ecology and Evolution, 4(2), 133-142. https://doi.org/10.1111/j.2041-210x.2012.00261.x

Neville, M. K., Glander, K. E., Brata, F., \& Rylands, A. B. (1988). The howling monkeys, genus Alouatta. Ecology and Behavior of Neotropical Primates. 2, 349-453.

Nieuwenhuis, R., te Grotenhuis, H. F., \& Pelzer, B. J. (2012). Influence. ME: Tools for detecting influential data in mixed effects models. The R Journal, 4(2),37-47.

Oliveira, D. A. G. (2002). Vocalizações de longo alcance de Alouatta fusca clamitans e Alouatta belzebul belzebul: Estrutura e contextos. Universidade de São Paulo. Instituto de Psicologia (unpublished doctoral dissertation).

Pika, S., Wilkinson, R., Kendrick, K. H., \& Vernes, S. C. (2018). Taking turns: Bridging the gap between human and animal communication. Proceedings of the Royal Society B: Biological Sciences, 285(1880), 20180598. https://doi.org/10.1098/rspb.2018.0598 
Pope, T. R. (2000). Reproductive success increases with degree of kinship in cooperative coalitions of female red howler monkeys (Alouatta seniculus). Behavioral Ecology and Sociobiology, 48(4), 253-267. https://doi.org/10.1007/s002650000236

Pougnault, L., Levréro, F., \& Lemasson, A. (2020). Conversation among primate species. In N., Masataka. The origin of language revisited (pp 73-96). Springer, Allemagne: Berlin. https://doi.org/10.1007/978-981-15-4250-3_4

Pougnault, L. (2020). Sur les traces de l'origine de nos conversations : étude comparative des règles d'interactions vocales chez les grands singes. EthoS Lab, Rennes 1 University. (unpublished doctoral dissertation).

Rendall, D., Cheney, D. L., \& Seyfarth, R. M. (2000). Proximate factors mediating" contact" calls in adult female baboons (Papio cynocephalus ursinus) and their infants. Journal of Comparative Psychology, 114(1), 36-46. DOI: 10.1037/0735-7036.114.1.36

Sacks, H., Schegloff, E. A., \& Jefferson, G. (1978). A simplest systematics for the organization of turn taking for conversation. In J., Schenkein (Ed.) Studies in the organization of conversational interaction (pp. 7-55). Elsevier, Academic Pres. https://doi.org/10.2307/412243

Schön, M. A. (1971). The anatomy of the resonating mechanism in howling monkeys. Folia Primatologica, 15(1-2), 117-132. https://doi.org/10.1159/000155371

Sekulic, R. (1982). The function of howling in red howler monkeys (Alouatta seniculus). Behaviour, 81(1), 38-54. https://doi.org/10.1163/156853982X00517

Snowdon, C. T. (2001). From primate communication to human language. In F. de Wall (Ed.) Tree of Origin. What Primate Behavior Can Tell Us about Human Social Evolution, (pp. 193-227). Harvard University Press, USA.

Stanford, C. (1998). Predation and male bonds in primate societies. Behaviour, 135(4), 513-533. https://doi.org/10.1163/156853998793066212

Stivers, T., Enfield, N. J., Brown, P., Englert, C., Hayashi, M., Heinemann, ... Levinson, S.C. (2009). Universals and cultural variation in turn-taking in conversation. Proceedings of the National Academy of Sciences, 106(26), 10587-10592. https://doi.org/10.1073/pnas.0903616106

Takahashi, D. Y., Fenley, A. R., Teramoto, Y., Narayanan, D. Z., Borjon, J. I., Holmes, P., \& Ghazanfar, A. A. (2015). The developmental dynamics of marmoset monkey vocal production. Science, 349(6249), 734-738. http:// doi.org/10.1126/science.aab1058.

Thieltges, H., Henry, L., Biquand, V., \& Deleporte, P. (2014). Short-Term Variations of Dialects in Short Songs of Two Species of Colonial Caciques (Cacicus). Acta Acustica United with Acustica, 100(4), 759-766. https://doi.org/10.3813/AAA.918755

Van Belle, S. (2015). Female participation in collective group defense in black howler monkeys (Alouatta pigra). American Journal of Primatology, 77(6), 595-604.

https://doi.org/10.1002/ajp.22380 
Van Belle, S., \& Estrada, A. (2020). The influence of loud calls on intergroup spacing mechanism in black howler monkeys (Alouatta pigra). International Journal of Primatology, 41(2), 265-286. https://doi.org/10.1007/s10764-019-00121-x

Van Belle, S., Estrada, A., \& Strier, K. B. (2011). Insights into social relationships among female black howler monkeys Alouatta pigra at Palenque National Park, Mexico. Current Zoology, 57(1), 17. https://doi.org/10.1093/czoolo/57.1.1

Van Belle, S., Estrada, A., Strier, K. B., \& Di Fiore, A. (2012). Genetic Structure and Kinship Patterns in a Population of Black Howler Monkeys, Alouatta pigra, at Palenque National Park, Mexico: Genetic Population Structure of Black Howlers. American Journal of Primatology, 74(10), 948-957. https://doi.org/10.1002/ajp.22047

Van Belle, S., Estrada, A., Ziegler, T. E., \& Strier, K. B. (2009). Sexual behavior across ovarian cycles in wild black howler monkeys (Alouatta pigra): Male mate guarding and female mate choice. American Journal of Primatology, 71(2), 153-164. https://doi.org/10.1002/ajp.20635

Van Belle, S., Estrada, A., \& Garber, P. A. (2014a). The function of loud calls in black howler monkeys (Alouatta pigra): Food, mate, or infant defense? American Journal of Primatology, 76(12), 1196-1206 https://doi.org/10.1002/ajp.22304

Van Belle, S., Garber, P. A., Estrada, A., \& Di Fiore, A. (2014b). Social and genetic factors mediating male participation in collective group defence in black howler monkeys. Animal Behaviour, 98, 7-17. https://doi.org/10.1016/j.anbehav.2014.09.023

Whitehead, J. M. (1987). Vocally mediated reciprocity between neighbouring groups of mantled howler monkeys, Alouatta palliata palliata. Animal Behaviour, 35, 1615-1627. https://doi.org/10.1016/S0003-3472(87)80054-4

Whitehead, J. M. (1989). The effect of the location of a simulated intruder on responses to longdistance vocalizations of mantled howling monkeys, Alouatta palliata palliata. Behaviour, 108(1-2), 73-103. https://doi.org/10.1163/156853989X00060

Whitehead, J. M. (1995). Vox Alouattinae: A preliminary survey of the acoustic characteristics of long-distance calls of howling monkeys. International Journal of Primatology, 16(2), 121-144. https://doi.org/10.1007/BF02700156

Whittaker, S., \& O’Conaill, B. (1997). The role of vision in face-to-face and mediated communication. In K. E. Finn, A. J. Sellen, \& S. B. Wilbur (Eds.), Computers, cognition, and work. Video-mediated communication (pp. 23-49). Lawrence Erlbaum Associates Publishers. https://doi.org/10.1023/A:1008717126658

Yoshida, S., \& Okanoya, K. (2005). Evolution of turn-taking: a bio-cognitive perspective. Cognitive Studies: Bulletin of the Japanese Cognitive Science Society, 12(3), 153-165. https://doi.org/10.11225/jcss.12.153

Zuur, A. F., Ieno, E. N., Walker, N. J., Saveliev, A. A., \& Smith, G. M. (2009). Zero-truncated and zero-inflated models for count data. In A.F., Zuur, E. N., Ieno, N. J.,Walker, A. A., Saveliev, \& G. 
607 M., Smith (Eds) Mixed effects models and extensions in ecology with $R$ (pp. 261-293). Springer, 608 USA: New York. https://doi.org/10.1007/978-0-387-87458-6_11

609

610 Data Availability Statement: The data that support the findings of this study are available from the 611 corresponding author upon reasonable request. 
Table 1. Characteristics of the six groups of black howler monkeys studied in two geographical locations.

\begin{tabular}{|c|c|c|c|c|c|c|c|c|}
\hline \multirow{2}{*}{$\begin{array}{c}\text { Geographical } \\
\text { location }\end{array}$} & \multirow{2}{*}{$\begin{array}{l}\text { Group } \\
\text { Name }\end{array}$} & \multicolumn{4}{|c|}{ Group composition } & \multirow[b]{2}{*}{$\begin{array}{l}\text { Contact } \\
\text { hours } \\
\text { number }\end{array}$} & \multirow[b]{2}{*}{$\begin{array}{l}\text { Observation } \\
\text { periods }\end{array}$} & \multirow[b]{2}{*}{$\begin{array}{l}\text { Sampled } \\
\text { sequences } \\
\text { number } \\
\end{array}$} \\
\hline & & $\begin{array}{l}\text { Matu } \\
\text { re } \\
\text { males } \\
\end{array}$ & $\begin{array}{l}\text { Mature } \\
\text { females }\end{array}$ & $\begin{array}{l}\text { Immatur } \\
\text { es males }\end{array}$ & $\begin{array}{l}\text { Immatur } \\
\text { es } \\
\text { females }\end{array}$ & & & \\
\hline \multirow[t]{3}{*}{$\begin{array}{c}\text { Palenque } \\
\text { National Park }\end{array}$} & $\mathrm{PK}$ & 3 & 3 & 0 & 1 & $291 \mathrm{~h}$ & $\begin{array}{c}\text { Feb. - Apr. } \\
\text { 2012, Feb. } \\
\text { 2014 }\end{array}$ & 35 \\
\hline & MT & 2 & 1 & 3 & 2 & $297 \mathrm{~h}$ & $\begin{array}{l}\text { Apr. - Jun. } \\
\text { 2012, Feb. } \\
2014\end{array}$ & 22 \\
\hline & BA & 2 & 2 & 2 & 0 & $300 \mathrm{~h}$ & $\begin{array}{c}\text { Jun. - May. } \\
\text { 2012, Feb. } \\
2014\end{array}$ & 29 \\
\hline \multirow[t]{3}{*}{$\begin{array}{c}\text { Fragment } \\
\text { forest patches }\end{array}$} & MG & 1 & 2 & 1 & 1 & $92 \mathrm{~h}$ & $\begin{array}{c}\text { Feb. - Mar. } \\
2014\end{array}$ & 7 \\
\hline & QL & 1 & 1 & 0 & 1 & $20 \mathrm{~h}$ & Feb. 2014 & 10 \\
\hline & CK & 1 & 2 & 1 & 1 & $48 \mathrm{~h}$ & $\begin{array}{c}\text { Feb. - Mar. } \\
\text { 2014) }\end{array}$ & 9 \\
\hline
\end{tabular}


617 Figure 1. Female's overlap and male's overlap avoidance. Spectrograms of extracts of howling 618 bouts involving two mature females (Fem 1 and 2) (a) and two mature males (Male 1 and 2) (b). 619 Spectrogram configuration: window type $=$ Hann. window size $=512$ samples; overlap $50 \%$.

620 Figure 2. Rates of vocal overlap vary with caller identity. Plots of predicted counts of the number 621 of overlapped calls on the (a) "Age of caller" (Immature vs Mature), and on the (b) "Sex of caller" 622 (Female vs Male) from six study groups of howler monkeys. Error bars represent the lower and 623 higher confidence interval estimate of the marginal effects (predicted counts) estimate.

624 Figure 3. Rates of vocal overlap vary with call types. Plots of predicted counts the number of 625 overlapped calls on the estimated effect of overlapped calls on the "Call type" emitted by six study 626 groups of howler monkeys, Error bars represent the lower and higher confidence interval estimate of the marginal effects (predicted counts) estimate.

Figure 4. Rates of vocal overlap vary with contexts. Plots of predicted counts of the number of overlapped calls on the "contexts" (Absent, distant and close neighbor) in four of our study groups of howler monkeys. Error bars represent the lower and higher confidence interval estimate of the marginal effects (predicted counts) estimate.

Figure 5. Rates of vocal overlap vary with the targeted sex. Plots of predicted counts of the number of overlapped calls by males and females in relation with the sex of the preceding caller: Female-Female (i.e., Female overlaps Female), Female-Male (i.e., Female overlaps Male), MaleFemale (i.e., Male overlaps Female), Male-Male (i.e., Male overlaps Male). Data come from two study groups of howler monkeys. Error bars represent the lower and higher confidence interval estimate of the marginal effects (predicted counts) estimate. 

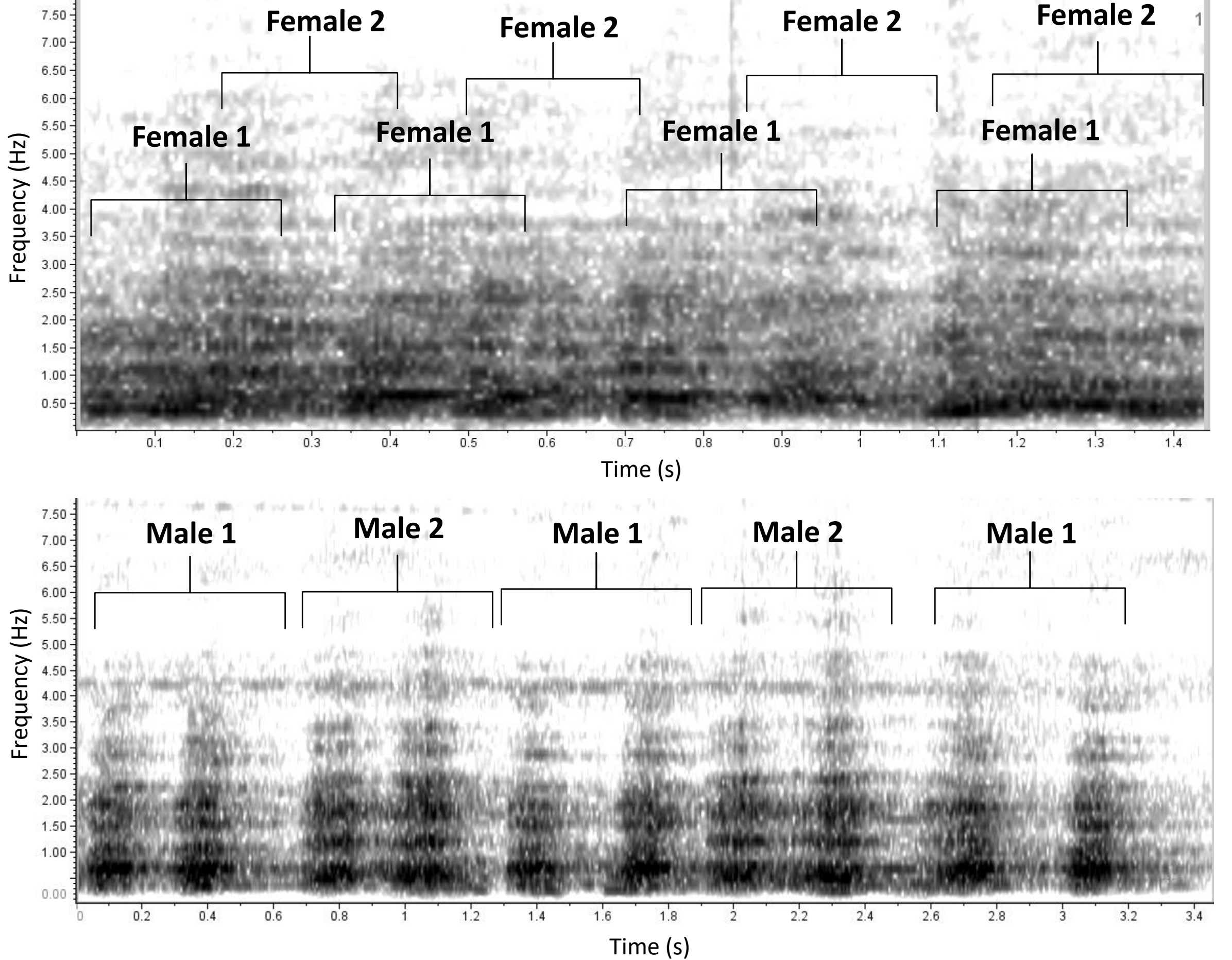


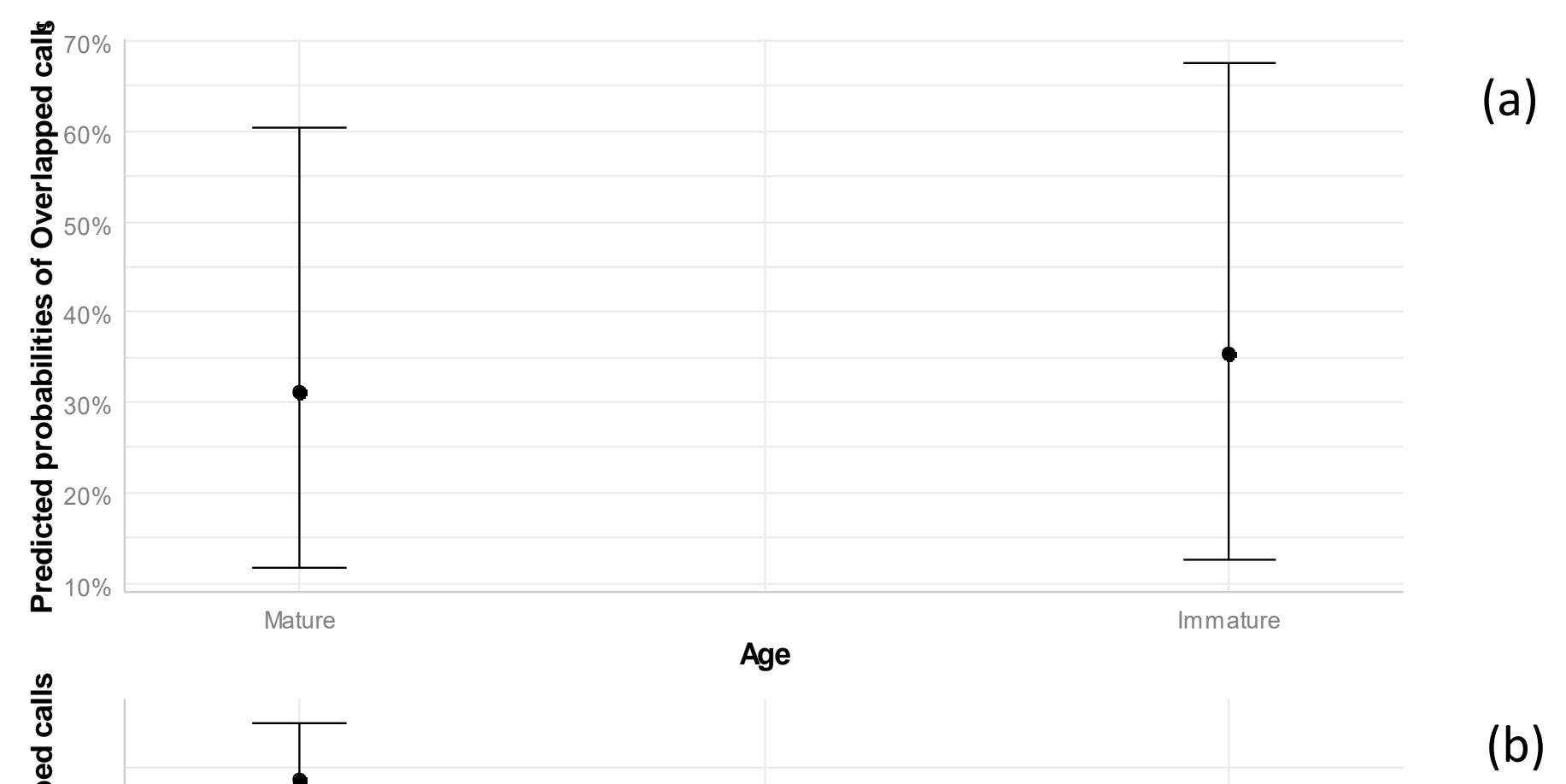

Sexe

(b) 



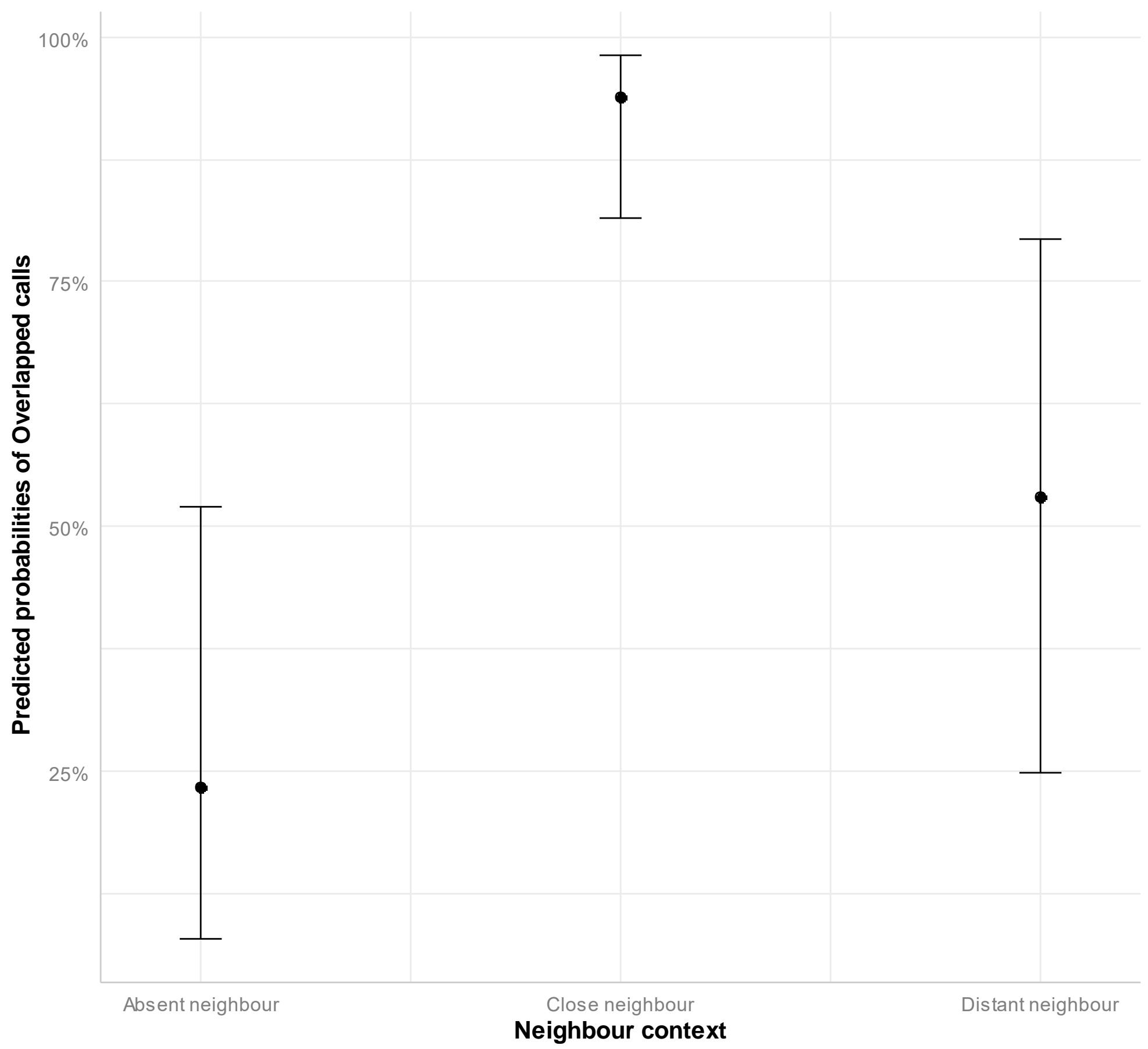




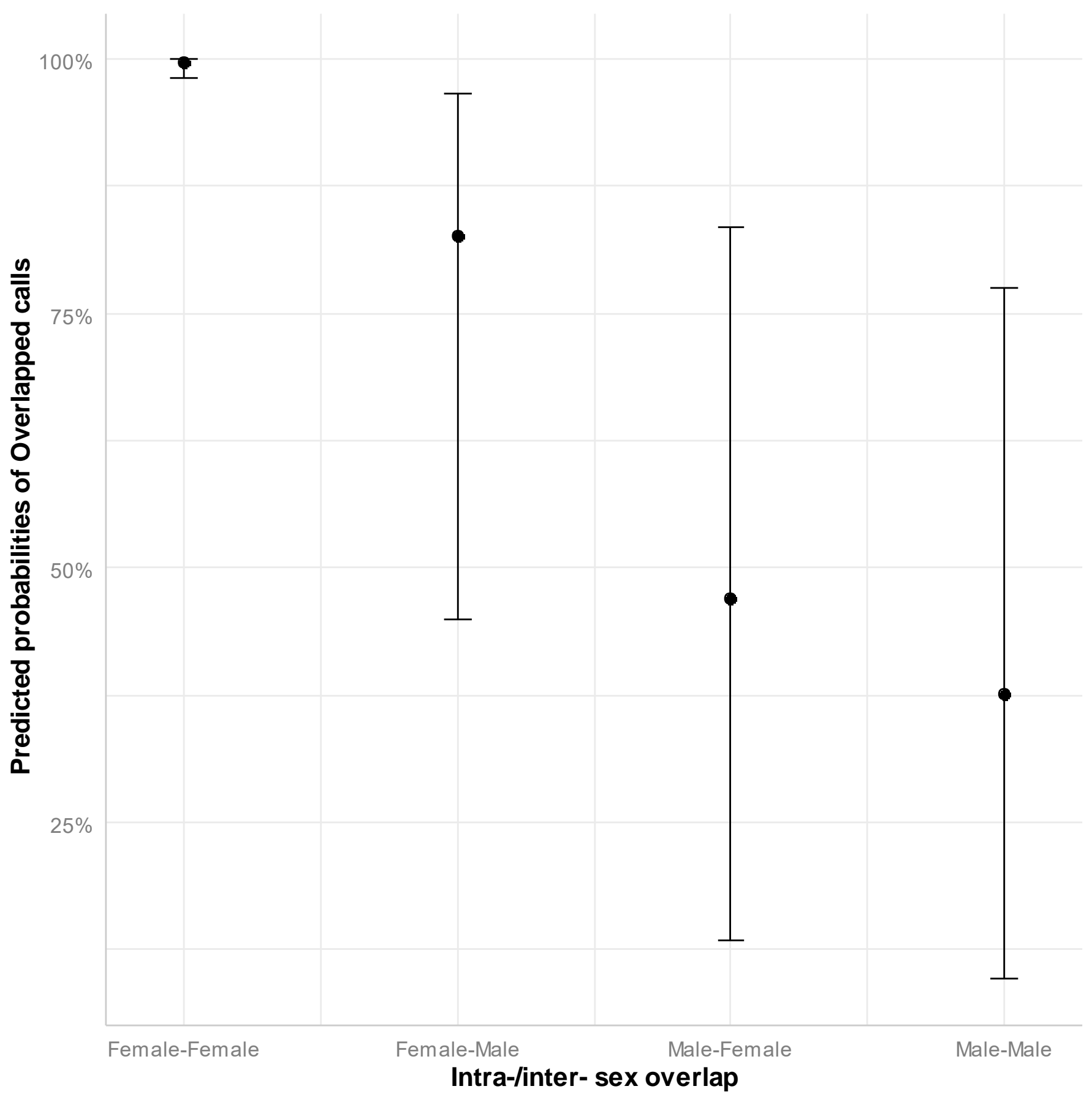


640

641 Outputs of all GLMM models

642

643 644

Random factors

Identity (intercept)

Sequence (intercept)

Group (intercept)
Variance

$S D$

9.599

3.098

2.856

1.69

1.49

1.22

\section{Fixed effects:}

\begin{tabular}{lllll} 
& Estimate & $S D$ & $Z$ value & $\operatorname{Pr}(>|z|)$ \\
(Intercept) & -0.9353 & 0.656 & -1.426 & 0.15394 \\
sexM & -3.0965 & 0.2838 & -10.912 & $<2.00 \mathrm{E}-16$ \\
ageIM & 1.1531 & 0.2719 & 4.241 & $2.23 \mathrm{E}-05$ \\
Agonistic & 6.3472 & 0.3603 & 17.615 & $<2.00 \mathrm{E}-16$ \\
Barks & 0.7219 & 0.2594 & 2.783 & 0.00539 \\
Grunt & 5.2505 & 0.2653 & 19.791 & $<2.00 \mathrm{E}-16$ \\
Roar & 6.6868 & 0.2579 & 25.923 & $<2.00 \mathrm{E}-16$ \\
RoarVariant & 5.0251 & 0.2578 & 19.494 & $<2.00 \mathrm{E}-16$ \\
& & & & \\
AIC & BIC & LogLik & deviance & df.resid \\
25516.1 & 25617.8 & -12747 & 25494.1 & 76715 \\
\hline
\end{tabular}

Factor 'Sex': 2 levels (M=Male, F=Female), Factor 'Age': 2 levels (M=Mature, IM=Immature), Factor 'Call type': 6 levels (barks, roars, roar variants, agonistic calls, affiliative calls, grunts) 


\section{APPENDIX 2}

- Results of the second full model (GLMM2) assessing the influence of contextual variations on vocal overlap

Model 2 = glmer(Calls overlapped $\sim$ neighbour_context $+(1 \mid$ group $)+(1 \mid$ sequence $)+(1 \mid$ identity $)$

\section{Random factors}

$\begin{array}{lll} & \text { Variance } & \text { SD } \\ \text { Identity (intercept) } & 20.984 & 4.581 \\ \text { Sequence (intercept) } & 1.878 & 1.37 \\ \text { Group (intercept) } & 1.979 & 1.407\end{array}$

Fixed effects

$\begin{array}{lllll} & \text { Estimate } & \text { SD } & \text { Z Value } & \operatorname{Pr}(>|z|) \\ \text { (Intercept) } & 0.25153 & 0.84002 & 0.299 & 0.765 \\ \text { neighbour_Close } & 2.66069 & 0.08808 & 30.207 & <2.00 \mathrm{E}-16 \\ \text { neighbour_Distant } & 0.23444 & 0.06012 & 3.899 & 9.65 \mathrm{E}-05\end{array}$

AIC BIC logLik deviance df.resid

$\begin{array}{lllll}37405.6 & 37460.4 & -18696.8 & 37393.6 & 67730\end{array}$

Factor 'neighbour_context': 3 levels (neighbour Close, neighbour Distant, neighbour absent) 
647

648

649

650

651

\section{APPENDIX 3}

- Results of the third full model (GLMM3) assessing whether the sexes of the exchanging partners influenced vocal overlap.

Model 3 = glmer(Calls overlapped $\sim$ suite $+(1 \mid$ group $)+(1 \mid$ sequence $)+(1 \mid$ identity $)$

\section{Random factors}

$\begin{array}{lll} & \text { Variance } & S D \\ \text { Identity (intercept) } & 17.604 & 4.196 \\ \text { Sequence (intercept) } & 3.809 & 1.952 \\ \text { Group (intercept) } & 1.043 & 1.022\end{array}$

\section{Fixed effects}

$\begin{array}{lllll} & \text { Estimate } & S D & \text { Z Value } & \operatorname{Pr}(>|z|) \\ \text { (Intercept) } & 5.525 & 0.861 & 6.412 & 2.12 \mathrm{E}-09 \\ \text { FM } & -4.066 & 0.215 & -18.893 & <2.00 \mathrm{E}-16 \\ \text { MF } & -5.173 & 0.345 & -14.979 & <2.00 \mathrm{E}-16 \\ \text { MM } & -5.927 & 0.342 & -17.309 & <2.00 \mathrm{E}-16\end{array}$

AIC BIC logLik deviance df.resid

$\begin{array}{lllll}20200.3 & 20261.1 & -10093.2 & 20186.3 & 43539\end{array}$

Factor 'suite': 4 levels ('FF'= female overlaps female, 'FM'= female overlaps male, 'MM'= male overlaps male, 'MF'= male overlap female). 